\title{
Necesidad del peritaje en la responsabilidad civil médica en Colombia - línea jurisprudencial
}

\author{
Need for expertise in medical civil liability in Colombia - jurisprudential line
}

\section{Diego Juan Jiménez Quiceno}

Abogado. Especialista en Derecho Administrativo. Especialista en Derecho Comercial. Estudiante de la Maestría en Derecho Constitucional de la Universidad Libre de Pereira. Magistrado de la Sala Única del Tribunal Superior de Quibdó. Exjuez civil municipal de Medellín y Cali. Exjuez civil del circuito de Medellín y Cartago. Excatedrático en asignaturas de derecho privado en la Universidad Cooperativa sede Cartago. Miembro del Instituto Colombiano de Derecho Procesal (ICDP). Correo electrónico: quiceno12@hotmail. com.

Fecha de recepción: junio de 2020

Fecha de aprobación: enero de 2021

Para citar este artículo / To reference this article

Necesidad del peritaje en la responsabilidad civil médica en Colombia - línea jurisprudencial. Inciso, 22(2) ; $263-282$

DOI: http://dx.doi.org/10.18634/incj.22v.2i.1041

\section{Resumen}

Este artículo tiene como propósito presentar el debate vigente en el ámbito jurídico colombiano respecto de la necesidad o no del peritaje en los procesos de responsabilidad civil médica, a través del análisis de la jurisprudencia de la Sala de Casación Civil de la Corte Suprema de Justicia. Enseñando, para el efecto, luego de un sucinto contexto de dicho medio probatorio en la materia, la descripción de las sentencias analizadas, así como la línea jurisprudencial que se elaboró, la cual refleja, el tratamiento que ha recibido históricamente la problemática en uno y otro sentido. Resultando trascendental, la discusión reciente en torno a si la "sana crítica", como criterio valorativo del juez, debe integrarse, a más del sentido común y las reglas de la experiencia, por un conocimiento básico o avanzado de las ciencias. Pudiéndose concluir que, según la referida línea jurisprudencial, ha de operar lo primero, y que, con fundamento en ello, el experticio, en tales trámites, se instituye, generalmente, como un requisito necesario para gestionar el pleito y emitir el fallo.

Palabras clave: responsabilidad civil, jurisprudencia, peritaje, sana critica. 


\begin{abstract}
The purpose of this article is to present the current debate in the Colombian legal field, regarding the need or not, of the expertise in medical civil liability processes, through the analysis of the jurisprudence of the Sala de Casación Civil de la Corte Suprema de Justicia. Teaching, for this purpose, after a succinct context of the evidence on the matter, the description of the analyzed sentences, as well as the jurisprudential line that was elaborated, which reflects the treatment that this problem has historically received in one and another sense. Being transcendental, the recent discussion about whether "sound criticism", as the judge's evaluative criterion, must be integrated, in addition to common sense and the rules of experience, for a basic or advanced knowledge of the sciences. Being able to conclude that, according to the referred jurisprudential line, the first must operate, and based on this, the expertise, in such procedures, is generally established as a necessary requirement to manage the lawsuit and issue the ruling.
\end{abstract}

Keywords: civil responsibility, jurisprudence, expertise, sound criticism

\title{
Introducción
}

El Código General del Proceso -CGP- Ley 1564 de 2012 (Congreso de la República, Diario Oficial No. 48.489 de 12 de julio de 2012), establece la procedencia de la prueba pericial para verificar hechos que interesen al juicio y requieran especiales conocimientos científicos, técnicos o artísticos, ordenando al juez, además, decretarlo de oficio, cuando sea necesaria para esclarecer el objeto de la controversia, debiendo apreciarlo conforme las reglas de la sana crítica, teniendo en cuenta la solidez, claridad, exhaustividad, precisión y calidad de sus fundamentos, la idoneidad del perito y su comportamiento en la audiencia, así como las demás pruebas que obren en el proceso. Evidenciándose entonces, en tales eventos, esto es, en aquellos donde a más del problema jurídico en sí mismo, se suscita otro de carácter científico, un escenario, si se quiere, problemático, en torno al alcance del dictamen pericial en el trámite de los procesos judiciales a efectos de que el juez resuelva de una manera idónea las controversias sometidas a su conocimiento, ocupando esta temática la atención de la doctrina y la jurisprudencia de la responsabilidad civil médica colombiana desde sus albores.

Siendo importante denotar, el entendimiento tradicional de la "sana crítica", como aquel criterio de valoración de la prueba conforme a un raciocinio lógico (Real Académia Española, 1998), integrado por el sentido común, las reglas de la experiencia y el conocimiento básico de los principios axiomáticos de las ciencias, tal y como se explica, por ejemplo, en las sentencias del 15 de septiembre de 2014, M.P. Margarita Cabello Blanco y 14 de noviembre de 2014 M.P. Fernando Giraldo Gutiérrez. Y por doctrinantes reconocidos como Jairo Parra Quijano (Parra Quijano, La prueba pericial, 1994) y Martín Bermúdez Muñoz (Bermúdez Muñoz, 2012).

Emergiendo, sin embargo, con data cercana, una ardua discusión en la academia y en sede jurisdiccional, en torno a la inclusión o no en la "sana critica", del conocimiento avanzado de las ciencias, llámese, "literatura científica”, "estándares de la profesión" o "conocimiento científico 
avanzado", y que supondría, por tanto, la facultad-deber del juez de prescindir, incluso, del decreto y práctica del experticio en casos de la especie, así como de su desestimación vía refutación técnica al momento de la valoración, bajo el entendido que, como funcionario investido o empoderado del mencionado criterio valorativo, ha de resolver preferentemente con fundamento en él y no en las resultas del informe pericial, tal y como se registra en las sentencias del 30 de septiembre de 2016 y 28 de junio de 2017 de la Sala Civil de la Corte Suprema de Justicia, ambas con ponencia de Ariel Salazar Ramírez. Y en los escritos de Arthur Kaufmann (Kaufmann, 1999) y Rodrigo Rivera Morales (Javier Hernandez García citado por Rivera Morales, 2016), surgiendo por ello la motivación de establecer, si la prueba pericial, según la jurisprudencia de la Sala Civil de la Corte Suprema de Justicia, es necesaria o no en los procesos de responsabilidad civil médica.

\section{Métodos}

El mencionado cometido, se procuró a través de una investigación de carácter histórico-jurídica, empleando para su desarrollo el método de la construcción del precedente judicial propuesto por el profesor Diego López Mejía en su libro “El derecho de los jueces” (López Medina, 2015) , bajo el entendido de que las sentencias deben ser interpretadas en su conjunto como líneas jurisprudenciales y no como pronunciamientos aislados, la mayoría de las veces, citadas de manera anti-técnica para afirmar una postura de las Altas Cortes sin corroborar si se trata de la doctrina probable, leída dinámicamente, en el desarrollo de la línea jurisprudencial (López Medina, 2015).

En ese orden de ideas, previa contextualización breve a nivel normativo y doctrinal de la prueba pericial en la responsabilidad civil médica en Colombia, se dará cuenta de las sentencias analizadas y de la línea jurisprudencial que refleja el tratamiento que ha recibido históricamente la problemática en uno y otro sentido por parte de la Sala de Casación Civil de la Corte Suprema de Justicia, resultando trascendental, la discusión en torno a la aceptación o no del conocimiento avanzado de las ciencias como parte integral del criterio valorativo del juez "sana crítica". Para finalmente, presentar las conclusiones que de allí se desprenden.

\section{Contexto normativo y doctrinal}

El artículo 226 del Código General del Proceso -CGP-, establece la procedencia de la prueba pericial para verificar hechos que interesen al proceso y requieran especiales conocimientos científicos, técnicos o artísticos, indicando que, sobre un mismo hecho o materia, cada sujeto procesal solo podrá presentar un peritaje y que todo dictamen se rendirá por un perito. En tanto que el artículo 227 del mencionado estatuto, instituye que la parte que pretenda valerse de un experticio, deberá aportarlo en la respectiva oportunidad para pedir pruebas y que deberá ser emitido por institución o profesional especializado. Conforme el artículo 228 del mencionado código, la parte contra la cual se aduzca un dictamen pericial podrá solicitar la comparecencia del perito a la audiencia, aportar otro o realizar ambas actuaciones. Si lo primero, el perito debe comparecer al juzgado o tribunal a sustentar su informe, pudiendo la contraparte formular preguntas al experto de forma asertiva o insinuante, advirtiendo que la prueba no tendrá valor, sino se da la comparecencia del perito. 
Por su parte, el artículo 170 de la misma normativa, ordena que el juez deberá decretar pruebas de oficio, cuando sean necesarias para esclarecer los hechos objeto de la controversia. Reglándose, en los artículos 230 y 231 de dicho código, el dictamen decretado de oficio. Y en el artículo 232 ibidem, lo concerniente a la apreciación de este, disponiendo que el juez valorará el peritaje de acuerdo con las reglas de la sana crítica, teniendo en cuenta la solidez, claridad, exhaustividad, precisión y calidad de sus fundamentos, la idoneidad del perito y su comportamiento en la audiencia, y las demás pruebas que obren en el proceso.

La prueba pericial, se ha denominado como aquella que se obtiene de un perito, como auxiliar del juez, por faltarle o carecerle a este las posibilidades técnicas de realizarla eficazmente. La fuente de prueba la constituye el objeto de la peritación, el medio de prueba, el examen y las operaciones que el perito lleva a cabo y que se reflejan en su dictamen (Carnelutti, 2000). Para Devis Echandía, se trata de una actividad procesal desarrollada, en virtud de encargo judicial, por personas distintas de las partes del proceso, especialmente calificadas por sus conocimientos técnicos, artísticos o científicos, mediante la cual suministra al juez argumentos o razones para la formación de su convencimiento respecto de ciertos hechos cuya percepción o cuyo entendimiento escapa a las aptitudes del común de las gentes (Devis Echandía, 1974). Y según Jairo Parra Quijano, se requieren conocimientos especializados, es decir, de aquellos que escapan a las culturas de las gentes, puede y debe recurrirse a quienes, por sus estudios, experiencia, etcétera, los posean. (Parra Quijano, Manual de derecho probatorio, 2004)

Uno de los campos relevantes en el que tiene un papel fundamental el dictamen pericial, es en el proceso de responsabilidad civil médica, ya que cada vez es más común que ante la jurisdicción civil se interpongan demandas en las que se pretende la declaratoria de responsabilidad, tanto a profesionales de la salud, como a entidades que prestan esa clase de servicios, por negligencia, violación a la lex artis, descuidos o cualquier otro tipo de error u omisión que pudiese suceder durante la práctica de dicha actividad.

Resultando trascendental, la discusión en torno a la aceptación o no del conocimiento avanzado de las ciencias como parte integral del criterio valorativo del juez "sana crítica". Pues mientras algunos autores como Jairo Parra Quijano (Parra Quijano, La prueba pericial, 1994), Martín Bermúdez Muñoz (Bermúdez Muñoz, 2012), Jordi Nieva Fenoll (Nieva Fenoll, 2010) y Jimmy Rojas Suárez (Rojas Suarez, 2014), sostienen que el propósito del dictamen pericial es el de garantizar la contradicción y la socialización del fallo, aportando conocimientos al trámite en asuntos en los que el juez no tiene ese saber especializado, por lo que, en materias como la medicina, si bien los hechos se acreditan con probanzas documentales como la historia clínica o los testimonios técnicos, la valoración de tales hechos, que es en últimas, la que permite afirmar la responsabilidad, debe, generalmente, ${ }^{1}$ obtenerse con la opinión de un perito.

Otros tratadistas como Arthurt Kaufmann (Kaufmann, 1999) y Rodrigo Rivera Morales (Javier Hernandez García citado por Rivera Morales, 2016), argumentan que para la valoración del peritaje no es suficiente la "sana critica", pues resulta inconsistente expresar que con el sentido común se pueda sopesar un conocimiento altamente especializado, fuera del alcance de la

1 Explicando tales doctrinantes que, en casos de poca complejidad y especificidad, podría excepcionalmente prescindirse de la prueba pericial. 
cultura media, no bastando con el control de los factores externos. Debiendo además, el juez, señalar con claridad el juicio fáctico que deriva de la pericia y las razones para dar como válidas las conclusiones del perito, teniendo en cuenta que los patrones formales para establecer el valor material de las hipótesis probatorias, generalmente, son implementados de manera natural por los jueces, quienes no necesitan tener profundos conocimientos teóricos de tales asuntos para elaborar razonadamente sus inferencias sobre los hechos, pues su ingenio, preparación jurídica y experiencia, les basta para darse cuenta de si una conclusión de esa naturaleza es concluyente o, por el contrario, poco probable o contraevidente.

\section{Descripción de las sentencias analizadas}

Conforme lo instruido por la metodología de elaboración de líneas jurisprudenciales (López Medina, 2015), se inició la búsqueda, consciente de la diferencia existente entre los descriptores genéricos propios de los índices de jurisprudencia preparados y que, para el caso, corresponderían a las categorías de "responsabilidad civil médica" y "prueba pericial", con el "patrón fáctico analógico" pretendido, esto es, "la necesidad de la prueba pericial en los procesos de responsabilidad civil médica", a efectos de identificar de manera adecuada las "sentencias hito" 2 de la línea. Actividad que tuvo, como primera tarea, la obtención de las "sentencias arquimédicas". ${ }^{3}$

Se consultó entonces, la relatoría de la Corte Suprema de Justicia, específicamente, la jurisprudencia de la Sala de Casación Civil, respecto de los procesos de "responsabilidad médica", encontrándose 71 sentencias, cuyos descriptores fueron revisados, buscando, en principio, hallar tópicos alusivos a la "prueba pericial", identificando dentro de dicha muestra, 27 sentencias que cumplían con tal criterio. Y de manera coetánea, se repararon varias publicaciones en la materia, a fin de obtener otras referencias puntuales de sentencias, advirtiendo que en el libro del año 2019, "Responsabilidad médica en la especialidad civil" de la Escuela Judicial Rodrigo Lara Bonilla -EJRLB- autoría de Mónica Lucía Fernández Muñoz (Escuela Judicial Rodrigo Lara Bonilla, 2019), se consignaba un listado generoso de 35 providencias relativas a la temática, las cuales fueron igualmente examinadas respecto del asunto "prueba pericial" y, en concreto, de "la necesidad de la prueba pericial en los procesos de responsabilidad civil médica", reconociendo allí, 18 fallos, dentro de tal "patrón fáctico analógico".

Con base en sendos muestreos, se identificaron como "sentencias arquimédicas", las fechadas el 12 de enero de 2018, M.P. Luis Armando Tolosa Villabona y 28 de junio de 2017, M.P. Ariel Salazar Ramírez. A partir de las cuales, y mediante el recurso de "ingeniería en reversa" ${ }^{4}$, se empezó a diseñar el "nicho citacional" , orientado a reconocer las que fueran analogizables por los hechos y circunstancias al patrón fáctico, es decir, por el valor precedencial del fallo anterior relativo al experticio médico y no por su valor conceptual. Pues se observó que, en muchas de tales providencias, no se hacía alusión a peritajes médicos, sino, por ejemplo, actuariales, para calcular montos de indemnizaciones del daño u otros ${ }^{6}$. Así como también, fallos en los que se abordaba la necesidad de la prueba pericial y que si bien, eran reiteradamente citados en otras providencias si listadas, daban cuenta de temáticas diferentes a la responsabilidad civil médica,

2 Fundamentales de la línea, en las que la Alta Corporación trata de definir con autoridad una sub-regla de derecho.

3 Recientes y que en sus hechos relevantes tratan el mismo patrón fáctico del fenómeno investigado, sirviendo de apoyo para la construcción de la línea.

4 Realizar listado de las citaciones jurisprudenciales que la sentencia arquimédica contiene, replicando el procedimiento hasta formar el nicho citacional.

5 Conjunto de citaciones jurisprudenciales resultado de la ingeniería en reversa.

6 Ver, por ejemplo, la sentencia del 12 de junio de 1984, M.P. Pedro Lafont. 
escapando por ello, al objeto de la investigación7. Emanando entonces, las 18 sentencias, 2 salvamentos y 2 aclaración de voto, cuyo detalle, pasa a sintetizarse:

* Sentencia del 5 de marzo de 1940, M.P. Liborio Escallón. (Corte Suprema de Justicia Sala de Casación Civil, 1940) Se indicó que, en los casos de responsabilidad médica, para demostrar la relación de causalidad entre el acto médico y el daño sufrido por el paciente, el dictamen pericial era indispensable, puesto que se necesitaba conocimiento científico y este, era solamente suministrado por expertos. Dijo la Corte allí, que los actos médicos, eran hechos del dominio de la medicina, respecto de los cuales, no podía el juez, sin el auxilio o cooperación de peritos médicos, hacer deducciones o inferencias para atribuir culpa o negligencia por parte del profesional que los hubiese ejecutado. Que se requería la intervención de otros facultativos o peritos, que estudiaran y analizaran esos hechos, con criterio igualmente científico, y sometieran a la consideración del juez, sus conclusiones y conceptos. Refiriéndose a la prueba testimonial, explicó la Corporación, que no podía tener la fuerza probatoria de las declaraciones de expertos, porque solo podía explicarse un concepto especializado por medio de un dictamen pericial, diferente a lo que podían expresar testigos legos en la materia.

* Sentencia del 14 de marzo de 1942, M.P. José María Blanco. (Corte Suprema de Justicia, Sala de Casación Civil., 1942) Resaltó la importancia del peritaje, advirtiendo que para que fuera acogido por el fallador, debía estar debidamente fundado, haberse emitido justa y rectamente, con acierto, y apoyado en justas y acertadas apreciaciones.

* Sentencia del 14 de octubre de 1959, M.P. Hernando Morales. (Corte Suprema de Justicia, Sala de Casación Civil, 1959) Se manifestó que no obstante la importancia del dictamen pericial en los juicios de responsabilidad médica, si se encontraban dos de ellos y se quedaban cortos en sus análisis, o si eran opuestos en sus afirmaciones, debía acudirse a un tercero. Sin embargo, ante la ausencia de este, la prueba no podía quedar perfeccionada.

* Sentencia del 8 de mayo de 1990, MP. Eduardo García. (Corte Suprema de Justicia, Sala de Casación Civil, 1990) Se aseveró que el dictamen técnico de expertos médicos era indudablemente el medio probatorio que ofrecía mayor poder de convicción cuando se trataba de establecer las causas que produjeron el deceso de una persona por la actividad de otras.

* Sentencia del 30 de enero de 2001, M.P. José Ramírez. (Corte Suprema de Justicia, Sala de Casación Civil, 2001) Se dijo que, si el Tribunal no tenía los conocimientos indispensables para determinar las incidencias médicas trascendentales para la resolución del caso, resultaba imperioso decretar, de oficio, para llenar su ignorancia, un dictamen pericial, en aras de precisar con exactitud tales circunstancias. Pero como no lo había hecho, resultaba palpable la violación del artículo 179 del Código de Procedimiento Civil.

* Sentencia del 13 de septiembre de 2002, M.P. Nicolás Bechara. (Corte Suprema de Justicia, Sala de Casación Civil, 2002) Se argumentó que, a pesar de la vital importancia del dictamen pericial $7 \quad$ Ver, entre otras, las sentencias del 24 de agosto de 1982, M.P. Jorge Salcedo Segura; del 24 de marzo de 1998, M.P. José Antonio Castillo; y del 12 de febrero de 2008 M.P. Pedro Munar Cadena. 
en responsabilidad médica, no era dable tenerlo como plena prueba, si este, no se sustentaba en las probanzas allegadas al proceso, tal como la historia clínica, entre otros.

* Sentencia del 26 de septiembre de 2002, M.P. Jorge Santos Ballesteros. (Corte Suprema de Justicia, Sala de Casación Civil, 2002) Se estableció que cuando de asuntos técnicos se tratara, no eran el sentido común o las reglas de la vida, los criterios que exclusivamente debían orientar la labor de búsqueda de la causa jurídica adecuada, dado que no proporcionaban elementos de juicio necesarios, en vista del conocimiento especial que se necesitaba, por lo que, a no dudarlo, cobraba especial importancia, la dilucidación técnica, que brindara al proceso, esos elementos propios de la ciencia, no conocidos por el común de las personas y, de suyo, solo familiar en menor o mayor medida a aquellos que la practicaban y que, en últimas, daban, con carácter general, las pautas que había de tener en cuenta el juez, para atribuir a un antecedente, la categoría jurídica de causa.

En otras palabras, que un dictamen pericial, en conjunto con documentos técnicos científicos o testimonios de la misma índole, entre otras pruebas, podrían ilustrar al juez sobre las reglas técnicas que la ciencia de que se tratara, tuvieran decantadas en relación con la causa probable o cierta de la producción del daño que se investigaba. Así, con base en la información suministrada, podría el juez, ahora sí, aplicando las reglas de la experiencia común y las propias de la ciencia, dilucidar con mayor margen de certeza si uno o varios antecedentes eran causas o, como decían los escolásticos, meras condiciones que coadyuvaban, pero no ocasionaban.

* Sentencia del 22 de julio de 2010, M.P. Pedro Munar Cadena. (Corte Suprema de Justicia, Sala de Casación Civil, 2010) Aunque en algunos de sus apartes, realzó la necesidad de la prueba pericial. Paradójicamente, al momento de adoptar la decisión, se basó en abundante literatura médica, relativa a la anestesiología, la cual contrastó con las actuaciones médicas del caso, arribando a sus propias conclusiones, no obstante, la ausencia en el plenario de dictámenes médicos que sustentaran la bibliografía consultada.

* Sentencia del 17 de noviembre de 2011, M.P. William Namén. (Corte Suprema de Justicia, Sala de Casación Civil, 2011) Citando la providencia del 22 de julio de 2010, apuntó que, tratándose de la responsabilidad civil extracontractual médica, el juez, con sujeción a las normas jurídicas y de la mano de las reglas de la experiencia, el sentido común, la ciencia o la lógica, habría de deducir ciertas presunciones, relativas a la culpa galénica, sin que fuese admisible la aplicación de criterios generales que, sistemática e invariablemente, quebrantaran las reglas de distribución de la carga de la prueba previstas en el ordenamiento. Debiendo establecerse su mérito probatorio, de acuerdo con las reglas de la sana crítica y ser apreciada en conjunto con las pruebas restantes, máxime cuando su contenido se refería a conceptos que, en muchos casos, eran ajenos al conocimiento del funcionario.

* Sentencia del 30 de noviembre de 2011, M.P. Arturo Solarte. (Corte Suprema de Justicia, Sala de Casación Civil, 2011) Citando la providencia del 22 de julio de 2010, replicó las mismas consideraciones vertidas en el fallo del 17 de noviembre de 2011, acabado de describir. 
* Sentencia del 14 de diciembre de 2012, M.P. Ariel Salazar Ramírez. (Corte Suprema de Justicia, Sala de Casación Civil, 2012) Citando la sentencia del 26 de septiembre de 2002, indicó que cuando de asuntos técnicos se tratara, como en el caso de la responsabilidad médica, para que el juez se pudiera ilustrar sobre las reglas técnicas que la ciencia que se tratara tuviera decantadas, con relación a la causa probable o cierta del daño que se investigara, era necesario el dictamen pericial.

* Sentencia del 5 de noviembre de 2013, M.P. Arturo Solarte. (Corte Suprema de Justicia, Sala de Casación Civil, 2013) Se sostuvo que, colegir que un conjunto de testimonios constituía prueba contundente de la "diligencia y cuidado" del demandado y que, por lo mismo, no podía afirmarse que el médico actuó negligentemente o infringiendo los lineamientos de la lex artis ad hoc, constituía, sin duda, un error de hecho por suposición. Como quiera que, del contenido objetivo de los analizados testimonios, examinados individualmente y en conjunto, no afloraba que ese, hubiese sido el genuino alcance de tales probanzas y que, ante la duda, de oficio, debía haberse practicado un dictamen pericial, como prueba idónea para tomar la decisión que, en derecho, correspondía.

* Sentencia del 15 de septiembre de 2014, M.P. Margarita Cabello Blanco. (Corte Suprema de Justicia, Sala de Casación Civil, 2014) Citando las providencias del 5 de marzo de 1940 y 22 de julio de 2010, reprodujo iguales elucubraciones contenidas en los fallos del 17 y 30 de noviembre de 2011, detallados en líneas precedentes.

* Sentencia del 14 de noviembre de 2014, M.P. Fernando Giraldo Gutiérrez. (Corte Suprema de Justicia, Sala de Casación Civil, 2014)citando sentencia del 26 de septiembre de 2002, se argumentó que, en casos de responsabilidad médica, con miras a despejar cualquier duda sobre la culpa de los profesionales de la salud, la prueba procedente para verificar hechos que interesaran al proceso y requirieran especiales conocimientos científicos, técnicos o artísticos, era el dictamen pericial, sin que fuese válido acudir a la historia clínica o a la literatura médica, debidamente interpretada por una persona idónea para interpretarla.

* Sentencia del 2 de marzo de 2016, M.P. Margarita Cabello Blanco. (Corte Suprema de Justicia, Sala de Casación Civil, 2016) Se advirtió que la presencia en el plenario de un testigo técnico no ofrecía una explicación contundente para probar la culpa médica y, por ende, no era suficiente para fundar el fallo. Lo que debió hacerse en tal caso, citando la sentencia del 26 de septiembre de 2002, M.P. Jorge Santos Ballesteros, era haberse auxiliado de personas con especiales conocimientos científicos, es decir, acudir al dictamen pericial.

* Sentencia del 30 de septiembre de 2016, M.P. Ariel Salazar Ramírez. (Corte Suprema de Justicia, Sala de Casación Civil, 2016) En esta providencia, ante la ausencia de un dictamen pericial en el plenario, se acudió a la literatura médica, concluyendo, a través de esta, que el diagnóstico y tratamiento de la enfermedad que sufría la paciente, no había tenido una variación significativa en las últimas décadas, es decir, que los estándares médico-científicos no habían cambiado lo suficiente para comportar un conocimiento novedoso que escapara a la formación académica y profesional que debieron tener los médicos que atendieron a la paciente. 
Por lo que, cualquier persona de mediana capacidad intelectiva que se hubiera propuesto consultarla y, con mayor razón, los profesionales de la medicina la habrían entendido. Concluyendo que, a efectos de realizar el respectivo juicio de reproche culpabilístico, era necesario que el juez entrara a valorar los "estándares de la profesión" y los comparara con las acciones realizadas por el equipo médico para el tratamiento de una dolencia determinada, pues únicamente este balance o contraste, permitiría concluir si se actuó conforme a lo que el ordenamiento jurídico espera de ese sector o gremio profesional.

* Aclaración de voto de Luis Armando Tolosa Villabona, a la sentencia del 30 de septiembre de 2016. (Corte Suprema de Justicia, Sala de Casación Civil, 2016) Se indicó que, respecto de tal providencia, debían analizarse los problemas probatorios devenidos de la incorporación inopinada de estudios científicos o análisis desde diferentes posturas sobre la lex artis de la ciencia respectiva que aplicaban los profesionales de determinada área, como medios de convicción que no fueron debatidos en las instancias, con prescindencia del principio de contradicción, y que eran utilizados por el juez como fundamento para contrastar la práctica científica o el ejercicio profesional objeto de juzgamiento, otorgándoseles toda credibilidad, más allá de la que pudiera provenir del dictamen de los expertos, rendido en juicio y sometido al principio de contradicción.

* Sentencia del 28 de junio de 2017, M.P. Ariel Salazar Ramírez. (Corte Suprema de Justicia, Sala de Casación Civil, 2017) Apoyándose en criterios doctrinales como el de Arthurt Kaufmann, se aseveró que, en la actualidad, la sana crítica constituía el parámetro de valoración racional de todas las pruebas (arts. 187 C.P.C. y 176 C.G.P.). Y que esta, aludía a las reglas de la lógica formal y no formal, las máximas de la experiencia, las leyes, las teorías y conceptos científicos afianzados, así como los procedimientos, protocolos, guías y reglas, admitidos por los distintos ámbitos profesionales o técnicos, a las que está sujeta la actividad probatoria de los jueces y sus respectivas conclusiones sobre los hechos que interesan al proceso. Se aludió al término "conocimiento científico afianzado", como el compuesto por aquellas teorías, hipótesis o explicaciones formuladas por la comunidad científica o ilustrada, respaldadas por la evidencia de sus investigaciones o experimentos. Generalmente se encuentran publicadas en textos académicos, revistas indexadas, artículos especializados, memorias de conferencias o simposios, etc. Enfatizando que tenían la misma entidad o significación que consultar una enciclopedia, un libro de texto especializado, o un diccionario con el fin de desentrañar el significado de los conceptos generales que permitieran comprender y valorar la información suministrada por los medios de prueba.

Se advirtió que la sana crítica no era ni podía ser un medio de prueba, pues su función radicaba en servir de marco de referencia (hermenéutico) para la valoración razonada de las pruebas legal y oportunamente allegadas al proceso, por lo que, no se producía, practicaba, valoraba o controvertía, como si se hacía con los medios de prueba; aunque las partes tenían la posibilidad de aportar todos los elementos de prueba legalmente admisibles para aclarar, explicar, ampliar o limitar su aplicación. Y finalmente, que al igual que los demás criterios hermenéuticos, los conceptos de los expertos o especialistas, debían ser apreciados singularmente y en conjunto, conforme las reglas de la sana crítica, lo que requería tener en cuenta el método de valoración descrito líneas arriba, pues, de lo contrario, el sentenciador no estimaría razonadamente el acervo 
probatorio, sino que estaría resolviendo la controversia según su íntima convicción, opinión o creencia.

* Salvamento de voto de Luis Armando Tolosa Villabona, a la sentencia del 28 de junio de 2017. (Corte Suprema de Justicia, Sala de Casación Civil, 2017) Se argumentó que, la decisión, no debió fundarse en suposiciones valorativas de la prueba, ni mucho menos, a partir del contraste de una eventual o presunta "literatura científica médica", ajena a la propia realidad del acto médico juzgado, debidamente identificado y limitado por la parte demandante, como fundamento de la causa petendi. Puesto que, la sentencia realizó una serie de disquisiciones teóricas desde esa "literatura", mutándola en soporte fáctico y jurídico con "presunto criterio médico de certeza", y, además, como un medio probatorio adicional, para fulminar la responsabilidad médica deprecada, al margen de la prueba allegada a la foliatura, en los términos de la ley de enjuiciamiento correspondiente.

Que esas opiniones científicas, denominadas en la providencia "conocimiento científico afianzado", llegaron al proceso, sin haber surtido el trámite de contradicción, frente a la parte opositora, puesto que aparecieron como fuente bibliográfica, transformada en medio probatorio, erigido, inusualmente, como bastión para edificar la condena. Que su presencia era intempestiva en sede de casación, y fluía como medio de convicción para juzgar y proveer por parte de la Corte, en forma injustificada una decisión estimatoria, sin someterse a un análisis crítico con las pruebas técnicas de rigor, o al menos, con las aserciones de otros galenos especialistas en el área o de expertos de la lista de auxiliares de la justicia. No se sabía de ese acervo conceptual, si realmente era "aparente" o "fundado", ni cuál la validez de los criterios que, con pretensión científica, fueron expuestos al interior de la sentencia.

Que todo ese material, llegó a la comunidad cultural, científica y jurídica, y de ese modo, al proceso judicial, como fuente de conocimiento en un campo tan especializado y delicado, por medio de artículos publicados en revistas, libros o cualquier otro medio de conocimiento, que el mismo juez de la causa, consultó para apoyar la valoración probatoria o su grado de convicción, apropiándose de él, no solo como si fuera juez, sino también como autoridad de la disciplina científica respectiva objeto de juzgamiento, desbordando su tarea estelar de juzgar. Y finalmente, que la Corte tenía ya pautas claras para analizar asuntos relacionados con decisiones técnicas como la discutida, citando para el efecto las sentencias del 26 de septiembre de 2002, M.P. Jorge Santos Ballesteros y 14 de diciembre de 2012, M.P. Ariel Salazar Ramírez, resaltando respecto de este último Magistrado que, ahora actuaba como ponente de la sentencia de la cual disentía.

* Aclaración de voto de Aroldo Quiroz Monsalvo, a la sentencia del 28 de junio de 2017. (Corte Suprema de Justicia, 2017) Se discrepó, respecto de considerar los "conocimientos afianzados", como elemento de las reglas de la sana crítica, arguyendo que sería una carga muy pesada para los jueces, atentatoria del principio de la necesidad de la prueba, puesto que ante conocimientos especializados y desconocidos para este, las conclusiones sobre ese tipo de temas, debía estar sustentada en un dictamen pericial, ya que, de lo contrario, se desconocería el principio de la necesidad de la prueba, porque el fallo no se apoyaría en los medios suasorios regularmente allegados al proceso, sino en la investigación que, de forma intuitiva, adelantaría el fallador, sin 
que existieran elementos para establecer su corrección o pertinencia. Que, con tal proceder, además, se desconocerían los derechos de defensa y contradicción de la parte vencida, quien no tendría la posibilidad de contradecir las conclusiones o probar en contrario.

* Sentencia del 12 de enero de 2018 M.P. Luis Armando Tolosa Villabona. (Corte Suprema de Justicia, Sala de Casación Civil, 2018) Se resaltó la necesidad del dictamen pericial en juicios de responsabilidad médica, indicado que la jurisprudencia de la Corte, citando para ello la sentencia del 26 de septiembre de 2002, M.P. Jorge Santos Ballesteros, tenía sentado que un dictamen pericial, en conjunto con un documento técnico científico o un testimonio de la misma índole, entre otras pruebas, podrían ilustrar al juez, sobre las reglas que la ciencia de que se tratara. Que las historias clínicas y las fórmulas médicas, por lo tanto, en línea de principio, por sí, no serían bastantes para dejar sentado con certeza los elementos de la responsabilidad de que se trataba, porque sin la ayuda de otros medios de convicción que las interpretara, andaría el juez a tientas en orden a determinar, según se explicó en la sentencia citada del 26 de septiembre de 2012, si lo que se estaba haciendo en la clínica era o no un tratamiento adecuado y pertinente según las reglas del arte.

* Salvamento de voto de Ariel Salazar Ramírez, a la sentencia del 12 de enero de 2018. (Corte Suprema de Justicia, Sala de Casación Civil, 2018) Se argumentó que la atención debió centrarse en el cúmulo de pruebas que obraban en el expediente, tales como la guía del manejo de la patología y la historia clínica, puesto que no había que ser médico para darse cuenta de que los síntomas presentados por la paciente coincidían con las señales de alarma descritas en la guía médica. Que, en razonamiento sano y sencillo, se imponía admitir la conclusión más simple: como los síntomas que presentó la paciente correspondían a los descritos en la guía de manejo de dolencias, entonces el deber jurídico del personal médico que la atendió consistía en brindarle la atención consignada en el aludido protocolo, y si eso no ocurrió, había culpa médica.

\section{Línea jurisprudencial estructurada}

Con toda la información recolectada, esto es, con la estructura de "telaraña y los puntos nodales" se identificaron las sentencias "fundadoras", "hito"10 y "confirmatorias"11, confeccionándose entonces la línea jurisprudencial, cuya gráfica inicia con la formulación del problema jurídico propuesto: ¿Cuál ha sido el tratamiento jurisprudencial dado por la Sala Civil de la Corte Suprema de Justicia a la necesidad de la prueba pericial en los procesos de responsabilidad civil médica en Colombia?. Abriéndose a continuación el plano entre las dos soluciones extremas y, por ende, antagónicas. Esto es, al lado izquierdo: “El peritaje se torna como un medio probatorio imprescindible en dichos asuntos, dada la complejidad devenida de su especificidad". Y al derecho: "No es indispensable el experticio en tales juicios, por cuanto el juez ha de consultar

8 Gráfica de los puntos continuamente citados en las sentencias consultadas.

9 Fallo proferido por un alto tribunal en la etapa inicial de su ejercicio respecto del patrón fáctico analógico objeto de investigación.

10 Fundamentales de la línea, en las que la Alta Corporación trata de definir con autoridad una sub-regla de derecho.

11 Providencias que se ven a sí mismas como puras y simples aplicaciones de un principio o ratio contenido en una sentencia anterior. 
e interpretar por si mismo el conocimiento científico avanzado como parte del criterio valorativo de la sana critica". Graficando las sentencias, así como los salvamentos y aclaraciones de voto, según su cercanía a una u otra respuesta.

Como se advierte, la gran mayoría de los ítems graficados: 15 sentencias, 2 aclaraciones de voto y 1 salvamento de voto, se ubican en el lado izquierdo del plano. Aunque ninguno, en el extremo propiamente dicho, puesto que si bien, pregonan la necesidad de la prueba pericial en los procesos de responsabilidad civil médica en Colombia, no son imperativos en sentenciar que sin tal probanza, no sería dable declararla, puesto que explican que, en algunos casos excepcionales, esto es, cuando la culpa médica aflore de manera prístina de los otros medios probatorios obrantes en el plenario, como serían la historia clínica y/o los testimonios técnicos, acudiendo a la "sana crítica", conformada por el sentido común, las reglas de la experiencia y el conocimiento básico y no avanzado de las ciencias, sería dable que el Juez dedujera su existencia

A continuación se presenta la tabla contentiva de la línea jurisprudencial:

\begin{tabular}{|c|c|c|c|}
\hline & ojuisprudenciald dado porla Sala Civil de & 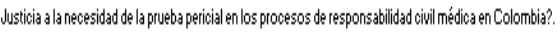 & \\
\hline 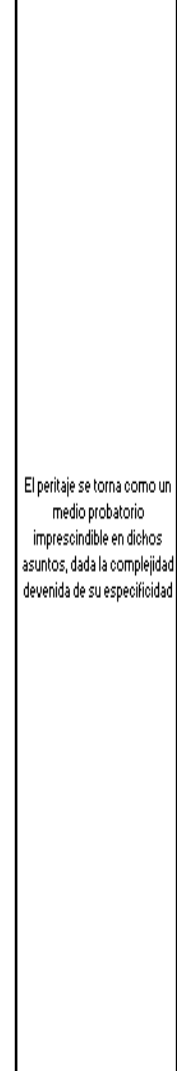 & 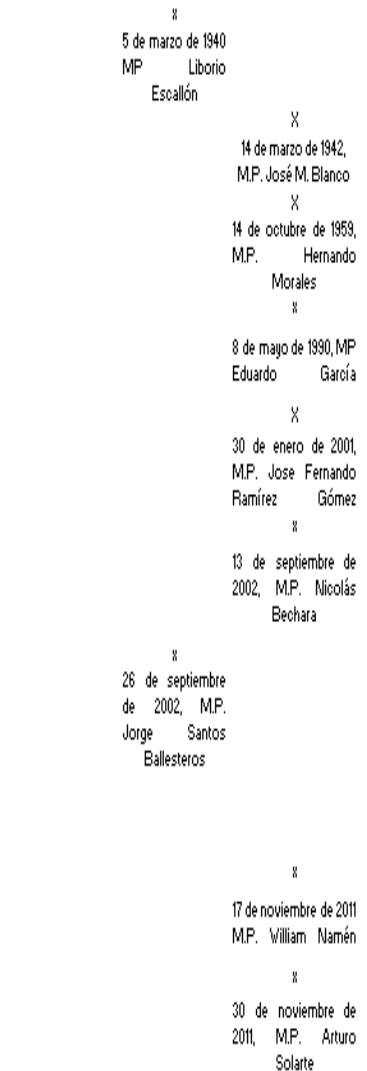 & $\begin{array}{l}\text { 22de iliode 2001,MP. } \\
\text { Pedto Munat Codena }\end{array}$ & 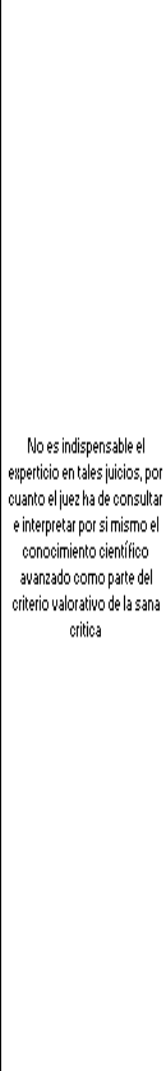 \\
\hline
\end{tabular}




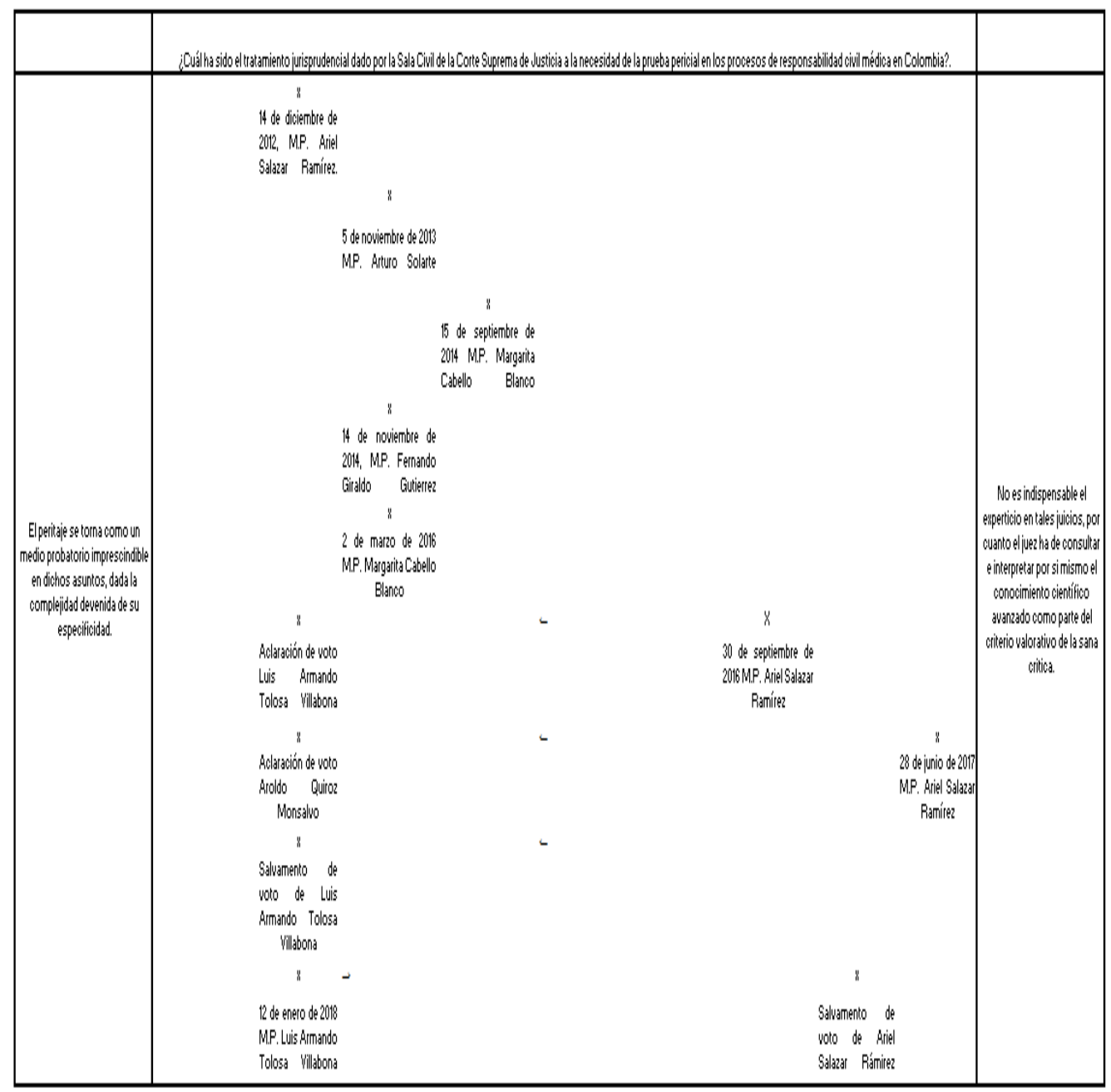

Fuente: Elaboración propia.

Tal y como se observa, tan sólo 2 sentencias y 1 salvamento de voto se situaron en la zona derecha de la gráfica, por considerar que la prueba pericial no era necesaria en los casos de responsabilidad médica en Colombia, con la particularidad, que tales pronunciamientos se dieron bajo la ponencia y autoría del Magistrado Ariel Salazar Ramírez. Resaltándose que la sentencia del 30 de septiembre de 2016, no se ubicó tan al extremo, por cuanto en su texto se abordó la temática, si se quiere, de una manera no tan categórica, haciéndose alusión a la expresión "estándares de la profesión" para significar aquellos estudios generalmente vertidos en literatura especializada que, según su criterio, cualquier persona de mediana capacidad intelectiva que se propusiera consultarla y, con mayor razón, los profesionales de la medicina, la entendería. 
Mientras que la sentencia del 18 de enero de 2018, si se ubicó en todo el extremo derecho, por cuanto defendió de una manera tajante, la prescindibilidad del peritaje, arguyendo que este podía y debía ceder ante el criterio hermenéutico de la "sana critica", integrado, entre otros, por el "conocimiento científico afianzado", el cual, se mostraba suficiente para tomar una decisión acertada. Siendo reiterado ese criterio, en el salvamento de voto suscrito por el mismo Magistrado, respecto de la sentencia del 18 de enero de 2018, M.P. Luis Armando Tolosa Villabona, dibujándose en ese mismo sector del plano, pero un poco más hacia la izquierda, por cuanto la defensa de tal postura no se mostró tan fulminante.

La sentencia del 22 de julio de 2010, M.P. Pedro Munar Cadena, fue posicionada en el centro de la gráfica, en virtud a que, si bien es cierto, dentro de sus consideraciones, relievó la necesidad de la prueba pericial médica en los juicios de responsabilidad civil médica, lo cual, evidentemente, la habría ubicado en el costado izquierdo del plano como una sentencia "confirmatoria" de la línea. Paradójicamente, al momento de adoptar la decisión, acudió al contenido de protocolos y guías médicas, para llegar a sus propias conclusiones, a pesar de la ausencia en el dossier de dictámenes médicos que sustentaran la bibliografía consultada, lo que implicaría de suyo, que debiera ubicarse en el costado derecho del plano, y que, incluso, pudiese considerarse como una sentencia "fundadora" de la línea contraria.

Sin embargo, ello no fue lo que tuvo lugar, por cuanto los pronunciamientos posteriores ubicados en el costado derecho del plano, ni siquiera la citan como referencia, en tanto que, varias de las providencias "confirmatorias" de la línea defensora de la necesidad del experticio, esto es, las sentencias del 17 de noviembre de 2011, M.P. William Namén; 30 de noviembre de 2011, M.P. Arturo Solarte; y 15 de septiembre de 2014, M.P. Margarita Cabello Blanco, la citan como sostén o apoyo de su postura. Razones por las que, se posicionó esa providencia en todo el centro de la gráfica, pero con flechas que de ella se desprenden hacía las "confirmatorias" del costado izquierdo, no ocurriendo lo propio respecto de las sentencias y pronunciamientos ubicados en el lado derecho.

La sentencia del 5 de marzo de 1940, M.P. Liborio Escallón, es considerada la providencia "fundadora" de la línea, por cuanto, según la investigación, fue el primer pronunciamiento de la Corte en la materia, entendiendo que, ante la ignorancia en una ciencia específica, respecto de un conocimiento especializado, esta solo podía ser absuelta por expertos, como en el caso de los actos médicos, dentro de los cuales el juez no debía, ni podía hacer deducciones para endilgar responsabilidades, por ser lego en la materia.

Las providencias que tienden más hacia el centro de la línea jurisprudencial en lugar de sus extremos (para el caso, el izquierdo), como es el caso de las sentencias del 14 de marzo de 1942, M.P. José María Blanco y 13 de septiembre de 2002, M.P. Nicolás Bechara, entre otras, se posicionan allí, porque, aunque tienen coincidencia en el "patrón fáctico analógico" e igual sentido de resolución, no asumieron en su texto una postura tan radical o marcada. Mencionaron eso sí, la necesidad de los dictámenes periciales, los cuales debían estar debidamente fundados, al grado que, de verificarse precariedad en sus análisis y conclusiones, debía acudirse a otro, pues, de lo contrario, no podría perfeccionarse tal medio probatorio. Que dicha probanza era la 
que ofrecía mayor poder de convicción, cuando se trataba de explicar fenómenos especializados, bajo el entendido de que el juez, siendo lego en la materia, tampoco podía acudir al arbitrio judicial para realizar una valoración sobre el particular. Instituyéndose, en tal sentido, como sentencias "confirmatorias" de la línea.

La sentencia del 26 de septiembre de 2002, M.P. Jorge Santos Ballesteros, no obstante poder concebirse como una sentencia "confirmatoria" de la línea, es considerada como la auténtica sentencia "hito" de la misma, puesto que realzó como ninguna otra lo había hecho antes, la necesidad del dictamen pericial médico en los juicios de responsabilidad civil médica en Colombia. Dicha providencia, fue citada posteriormente de manera sistemática en casi lo totalidad de los fallos que se graficaron en el costado izquierdo del plano.

Incluso, en la sentencia del 14 de diciembre de 2012, M.P. Ariel Salazar Ramírez, que, en tal sentido, se tornó en una sentencia "confirmadora" de la línea, al consignar en su motivación que, cuando de asuntos técnicos se tratara, no era el sentido común o las reglas de la experiencia, los criterios que exclusivamente debían orientar la labor de búsqueda de la causa jurídica adecuada, dado que no proporcionaban elementos de juicio, en vista del conocimiento especial, que en la responsabilidad médica se necesitaba, ya que cualquier persona del común, no conocía de un tema especializado.

Emergiendo de lo anterior, un punto crucial en el análisis, por cuenta de la evidente disparidad de criterios contenidos en el referido fallo y los restantes pronunciamientos ya comentados con ponencia y/o autoría del mencionado Magistrado Ariel Salazar Ramírez, esto es, las sentencias del 30 de septiembre de 2016 y 28 de junio de 2017, y el salvamento de voto a la sentencia del 12 de enero de 2018 del M.P. Luis Armando Tolosa Villabona. En los que, abogando por los criterios por él rotulados como "estándares de la profesión" o "conocimiento científico afianzado", se defendió la prescindencia del peritaje, aduciendo ahora, que cualquier persona de mediana capacidad intelectual que lo consultara, lo entendería. no siendo, por tanto, necesario el dictamen pericial, para tomar una decisión acertada.

Por su parte, la sentencia del 14 de noviembre de 2014, M.P. Fernando Giraldo Gutiérrez, si es del tipo "confirmatoria" de la línea que defiende la necesidad del peritaje médico, se destaca por contener mayores motivaciones en esa dirección, de allí su ubicación más hacia el extremo izquierdo del plano, al aducir que la prueba procedente para verificar hechos que interesaran al proceso y requirieran especiales conocimientos científicos, técnicos o artísticos, era el dictamen pericial, sin que fuese válido acudir a la historia clínica o a la literatura médica, debidamente interpretada por una persona idónea para interpretarla.

Posición que comparte en el esquema de la línea con las 2 aclaraciones de voto y el salvamento de voto formulados por los Magistrados Luis Armando Tolosa Villabona y Aroldo Quiroz Monsalve, justamente respecto de las 2 sentencias con ponencia del Magistrado Ariel Salazar Ramírez del 30 de septiembre de 2016 y 28 de junio de 2017, en los que, en esencia se arguyó, que la incorporación, como prueba, de esos "conocimientos afianzados", como elemento de las reglas de la "sana crítica", constituían una carga muy pesada para los jueces. Puesto que, en juicios 
de responsabilidad médica, al ser el juez, lego en la materia, las conclusiones debían estar soportadas en un dictamen pericial, pues, lo contrario, desconocería el principio de la necesidad de la prueba. Así como también, el principio de contradicción, al ser incluidos en la decisión, sin el previo conocimiento de las partes y, por ende, sin el correspondiente debate.

Finalmente, la sentencia del 12 de enero de 2018, M.P. Luis Armando Tolosa Villabona, se inscribe como "confirmatoria" de la línea, al resaltar la necesidad del dictamen pericial en juicios de responsabilidad médica, indicado que la jurisprudencia de la Corte tenía sentado que las historias clínicas y las fórmulas médicas, en línea de principio, por sí, no serían bastantes para dejar sentado con certeza los elementos de la responsabilidad, porque sin la ayuda de otros medios de convicción que las interpretara, como lo era por excelencia el peritaje, andaría el juez a tientas en orden a determinar, si lo que se estaba haciendo era o no un tratamiento adecuado y pertinente según las reglas del arte.

\section{Conclusiones}

A partir de los pronunciamientos estudiados de la Sala de Casación Civil de la Corte Suprema de Justicia, se advierte la existencia de una consolidada línea jurisprudencial en torno a la necesidad del dictamen pericial en los juicios de responsabilidad civil médica. Y ello, al margen de haberse revaluado el criterio primigenio de tenerlo como una herramienta para ilustrar al fallador en la materia, a fin que este la interiorizara y adoptara su decisión, al de concebirlo como una garantía de la contradicción y socialización del fallo, aportando conocimientos al trámite en asuntos en los que el juez no tiene ese saber especializado (Giraldo Gutierrez, 2014) (Tolosa Villabona, 2018). Que, en materias especializadas como la medicina, si bien los hechos se acreditan con probanzas documentales como la historia clínica o los testimonios técnicos, la valoración de tales hechos, que es, en últimas, la que permite afirmar la responsabilidad, debe generalmente ${ }^{12}$ obtenerse con la opinión de un perito.

Consideraciones compartidas por la doctrina mayoritaria en la materia ${ }^{13}$, aunque resistida en algunos pronunciamientos aislados de la Corporación ${ }^{14}$ y parte de los doctrinantes ${ }^{15}$, para quienes la "sana crítica", como criterio valorativo del juez (Artículo 232, Ley 1564 de 2012 - Código General del Proceso - , 2012), debe integrarse, a más del sentido común y las reglas de la experiencia, no por el tradicional conocimiento básico de las ciencias ${ }^{16}$, sino por los denominados "estándares de la profesión" o el "conocimiento científico afianzado". Siendo del caso resaltar, que los referidos pronunciamientos judiciales, se dieron bajo la ponencia y/o autoría del Magistrado Ariel Salazar Ramírez, y que según la lectura de la línea jurisprudencial, no tienen la entidad suficiente de considerarse como "fundadoras" o "hito" de una línea en el sentido contrario, sino más bien, de un "bandazo" de la Corporación, devenido, a lo mejor, de la persona del Magistrado que actuó como ponente y sus posiciones controversiales en esta y otras materias ${ }^{17}$.

\footnotetext{
12 Tener presente la salvedad de no necesidad de la prueba pericial para casos de poca complejidad y especificidad.

13 Ver Jairo Parra Quijano, Martín Bermúdez Muñoz, Jordi Nieva Fenoll y Jimmy Rojas Suárez,

14 Sentencias del 30 de septiembre de 2016 y 28 de junio de 2017, M.P. Ariel Salazar Ramírez.

15 Rodrigo Morales Riveras, Javier Hernández García y Arthur Kaufmann

16 Como se aborda más adelante en el presente artículo, la "sana crítica" se ha concebido tradicionalmente que se encuentra integrada por el sentido común, las reglas de la experiencia y el conocimiento básico de los principios axiomáticos de las ciencias.

17 Observe para el ejemplo la sentencia del 30 de septiembre de 2016, con ponencia del Magistrado Ariel Salazar Rámirez, en materia de reconfiguración de los elementos de la responsabilidad civil. Providencia que fue decretada solo por cinco (5) magistrados de los cuales dos (2) con aclaración de voto.
} 
Máxime si en cuenta se tiene, que posterior en el tiempo, se profirió la sentencia del 12 de enero de 2018, M.P. Luis Armando Tolosa Villabona, confirmatoria de la línea jurisprudencial tradicional y en total oposición a las sentencias con ponencia del Magistrado Ariel Salazar Ramírez. No estando demás sostener, que en tales fallos y de conformidad con lo establecido en el artículo 7 del Código General del Proceso, al apartarse de la doctrina probable de la Corte Suprema de Justicia, debía haberse expuesto de manera clara y razonada los fundamentos jurídicos que llevaban a tomar las decisiones en ese sentido. Resultando llamativo, además, el cambio de criterio del citado Magistrado, en relación con la sentencia del 14 de diciembre de 2012, donde obró como ponente.

Y si bien se advirtió en la providencia del 28 de junio de 2017, que la "sana crítica" no era ni podía ser un medio de prueba, pues su función radicaba en servir de marco de referencia (hermenéutico) para la valoración razonada de las pruebas legal y oportunamente allegadas al proceso, por lo que, no se producía, practicaba, valoraba o controvertía, como si se hacía con los medios de prueba. No deja de ser, por lo menos, llamativo, el eventual compromiso que puede tener el principio de contradicción, al ser incluido ese "conocimiento científico afianzado" consignado en textos académicos, revistas indexadas, artículos especializados, memorias de conferencias o simposios, en la decisión, sin el previo conocimiento de las partes y, por ende, sin el correspondiente debate.

\section{Referencias}

Bermúdez Muñoz, M. (2012). Del dictamen judicial al dictamen de parte. Bogotá, Colombia: NET Educativa.

Carnelutti, F. (2000). La prueba civil. Buenos Aires, Argentina.

Congreso de la República, Diario Oficial No. 48.489 de 12 de julio de 2012. (s.f.). Ley 1564 de 2012, Código General del Proceso -CGP-.

Corte Suprema de Justicia Sala de Casación Civil. (5 de marzo de 1940). M.P. Liborio Escallón. Obtenido de http://consultajurisprudencial.ramajudicial.gov.co:8080/WebRelatoria/csj/index. xhtml

Corte Suprema de Justicia. (2020). Consulta jurisprudencial de la rama judicial. Recuperado el 6 de junio de 2020, de http://consultajurisprudencial.ramajudicial.gov.co:8080/WebRelatoria/ csj/index.xhtml

Corte Suprema de Justicia, S. d. (28 de junio de 2017). Aclaración de voto del Magistrado Aroldo Quiroz Monsalvo a la sentencia del Magistrado Ariel Salazar Ramírez del. Obtenido de http:// consultajurisprudencial.ramajudicial.gov.co:8080/WebRelatoria/csj/index.xhtml

Corte Suprema de Justicia, Sala de Casación Civil. (14 de octubre de 1959). M.P. Hernando Morales. Obtenido de http://consultajurisprudencial.ramajudicial.gov.co:8080/WebRelatoria/ csj/index.xhtml

Corte Suprema de Justicia, Sala de Casación Civil. (8 de mayo de 1990). M.P. Eduardo García. Obtenido de http://consultajurisprudencial.ramajudicial.gov.co:8080/WebRelatoria/csj/index. xhtml 
Corte Suprema de Justicia, Sala de Casación Civil. (30 de enero de 2001). M.P. José Ramírez. Obtenido de http://consultajurisprudencial.ramajudicial.gov.co:8080/WebRelatoria/csj/index. xhtml

Corte Suprema de Justicia, Sala de Casación Civil. (26 de septiembre de 2002). M.P. Jorge Santos Ballesteros. Obtenido de http://consultajurisprudencial.ramajudicial.gov.co:8080/ WebRelatoria/csj/index.xhtml

Corte Suprema de Justicia, Sala de Casación Civil. (13 de septiembre de 2002). M.P. Nicolás Bechara. Obtenido de http://consultajurisprudencial.ramajudicial.gov.co:8080/WebRelatoria/ csj/index.xhtml

Corte Suprema de Justicia, Sala de Casación Civil. (22 de julio de 2010). M.P. Pedro Munar Cadena. Obtenido de http://consultajurisprudencial.ramajudicial.gov.co:8080/WebRelatoria/ csj/index.xhtml

Corte Suprema de Justicia, Sala de Casación Civil. (30 de noviembre de 2011). M.P. Arturo Solarte. Obtenido de http://consultajurisprudencial.ramajudicial.gov.co:8080/WebRelatoria/ csj/index.xhtml

Corte Suprema de Justicia, Sala de Casación Civil. (17 de noviembre de 2011). M.P. William Namén. Obtenido de http://consultajurisprudencial.ramajudicial.gov.co:8080/WebRelatoria/ csj/index.xhtml

Corte Suprema de Justicia, Sala de Casación Civil. (14 de diciembre de 2012). M.P. Ariel Salazar Ramirez.

Corte Suprema de Justicia, Sala de Casación Civil. (5 de noviembre de 2013). M.P. Arturo Solarte. Obtenido de http://consultajurisprudencial.ramajudicial.gov.co:8080/WebRelatoria/csj/index. xhtml

Corte Suprema de Justicia, Sala de Casación Civil. (14 de noviembre de 2014). M.P. Fernando Giraldo Gutierrez. Obtenido de http://consultajurisprudencial.ramajudicial.gov.co:8080/ WebRelatoria/csj/index.xhtml

Corte Suprema de Justicia, Sala de Casación Civil. (15 de septiembre de 2014). M.P. Margarita Cabello Blanco. Obtenido de http://consultajurisprudencial.ramajudicial.gov.co:8080/ WebRelatoria/csj/index.xhtml

Corte Suprema de Justicia, Sala de Casación Civil. (30 de septiembre de 2016). Aclaración de voto del Magistrado Luis Armando Tolosa Villabona a la sentencia del Magistrado Ariel Salazar Ramirez del. Obtenido de http://consultajurisprudencial.ramajudicial.gov.co:8080/ WebRelatoria/csj/index.xhtml

Corte Suprema de Justicia, Sala de Casación Civil. (30 de septiembre de 2016). M.P. Ariel Salazar Ramírez. Obtenido de http://consultajurisprudencial.ramajudicial.gov.co:8080/WebRelatoria/ csj/index.xhtml 
Corte Suprema de Justicia, Sala de Casación Civil. (2 de marzo de 2016). M.P. Margarita Cabello Blanco. Obtenido de http://consultajurisprudencial.ramajudicial.gov.co:8080/WebRelatoria/ csj/index.xhtml

Corte Suprema de Justicia, Sala de Casación Civil. (28 de junio de 2017). Aclaración de voto del Magistrado Luis Armando Tolosa Villabona a la sentencia del Magistrado Ariel Salazar Ramirez del. Obtenido de http://consultajurisprudencial.ramajudicial.gov.co:8080/WebRelatoria/csj/ index.xhtml

Corte Suprema de Justicia, Sala de Casación Civil. (28 de junio de 2017). M.P. Ariel Salazar Ramírez. Obtenido de http://consultajurisprudencial.ramajudicial.gov.co:8080/WebRelatoria/ csj/index.xhtml

Corte Suprema de Justicia, Sala de Casación Civil. (12 de enero de 2018). M.P. Luis Armando Tolosa Villabona. Obtenido de http://consultajurisprudencial.ramajudicial.gov.co:8080/ WebRelatoria/csj/index.xhtml

Corte Suprema de Justicia, Sala de Casación Civil. (12 de enero de 2018). Salvamento de voto del Magistrado Ariel Salazar Ramírez a la sentencia del Magistrado Luis Armando Tolosa Villabona del. Obtenido de http://consultajurisprudencial.ramajudicial.gov.co:8080/WebRelatoria/csj/ index.xhtml

Corte Suprema de Justicia, Sala de Casación Civil. (14 de marzo de 1942). M.P. José M. Blanco. Obtenido de http://consultajurisprudencial.ramajudicial.gov.co:8080/WebRelatoria/csj/index. xhtml

Devis Echandía, H. (1974). Teoría General de la Prueba (3 ed., Vol. II). Buenos Aires, Argentina.

Escuela Judicial Rodrigo Lara Bonilla. (2019). Módulo de Aprendizaje Autodirigido. Plan de formación de la rama judicial, responsabilidad médica en materia civil. (M. L. Muñoz, Ed.) Bogotá, Colombia.

Javier Hernandez García citado por Rivera Morales, R. (2016). Prolegómenos de la prueba pericial y prueba científica en el CGP. En I. C. Procesal, XXXVII Congreso Colombiano de Derecho Procesal (pág. 621 y ss.). Bogotá.

Kaufmann, A. (1999). En Filosofía del Derecho (pág. 159). Bogotá: Universidad Externado de Colombia.

López Medina, D. E. (2015). Obediencia judicial y administrativa de los precedentes de las Altas Cortes en Colombia: dos concepciones del fin y uso de la jurisprudencia como fuente del derecho. Universidad de los Andes.

Nieva Fenoll, J. (2010). En J. Nieva Fenoll, La valoración de la prueba (pág. 285). Madrid: Marcial Pons. 
Parra Quijano, J. (1994). La prueba pericial. En J. Parra Quijano, Tratado de la prueba judicial. Bogotá: Librería Ediciones del Profesional.

Parra Quijano, J. (2004). Manual de derecho probatorio (14 ed.). Bogotá: Ediciones del profesional.

Real Académia Española. (1998). sana crítica. Diccionario del español jurídico, 2020. Obtenido de https://dej.rae.es/lema/sana-crítica

Rojas Suarez, Y. (2014). XXXV Congreso Colombiano de Derecho Procesal. En I. C. Procesal, La prueba pericial en el nuevo CGP (pág. 414 y ss.). 